\title{
Enteral feeding for very low birth weight infants: reducing the risk of necrotising enterocolitis
}

M Chauhan, G Henderson and W McGuire

Arch. Dis. Child. Fetal Neonatal Ed. 2008;93;162-166; originally published online 15 Nov 2007;

doi:10.1136/adc.2007.115824

Updated information and services can be found at:

http://fn.bmj.com/cgi/content/full/93/2/F162

\section{These include:}

References This article cites 37 articles, 19 of which can be accessed free at: http://fn.bmj.com/cgi/content/full/93/2/F162\#BIBL

Rapid responses You can respond to this article at: http://fn.bmj.com/cgi/eletter-submit/93/2/F162

Email alerting Receive free email alerts when new articles cite this article - sign up in the box at service the top right corner of the article

Notes

To order reprints of this article go to:

http://journals.bmj.com/cgi/reprintform

To subscribe to Archives of Disease in Childhood - Fetal and Neonatal Edition go to:

http://journals.bmj.com/subscriptions/ 


\title{
Enteral feeding for very low birth weight infants: reducing the risk of necrotising enterocolitis
}

\author{
M Chauhan, ${ }^{1}$ G Henderson, ${ }^{2}$ W McGuire ${ }^{1}$
}

${ }^{1}$ Australian National University Medical School, Canberra, Australia; ${ }^{2}$ Griffith University, Brisbane, Australia

Correspondence to: Dr W McGuire, Centre for Newborn Care, The Canberra Hospital, ACT 2606, Australia william.mcguire@act.gov.au

Accepted 30 October 2007 Published Online First 15 November 2007

\section{ABSTRACT}

The principal modifiable risk factors for necrotising enterocolitis (NEC) in very low birth weight infants relate to enteral feeding practices. Evidence exists that feeding with formula milk increases the risk of NEC. Currently, only limited data are available on the effect of the timing of feed introduction and advancement on the risk of developing NEC. Large, multicentre randomised controlled trials of these strategies are needed. Other promising interventions that merit further evaluation include the use of prebiotics and probiotics, and the avoidance of exposure to $\mathrm{H}_{2}$-receptor antagonists.

Necrotising enterocolitis (NEC) affects about $5 \%$ of very low birth weight (VLBW) infants. Short gestational age at birth is the major risk factor. Although treatment with antenatal corticosteroids reduces the risk of developing NEC by $50 \%$, the incidence of NEC in VLBW infants has not changed markedly in the past 20 years, presumably because of increases in early neonatal survival rates for extremely preterm infants. The mortality rate in infants with confirmed NEC is greater than $20 \%$. Long-term morbidity can include neurological disability, the consequence of undernutrition and associated infection during a very vulnerable period of growth and development. ${ }^{1-3}$

Given these levels of morbidity and mortality, better preventative strategies are needed. Most VLBW infants who develop NEC have received enteral milk feeds and it has long been postulated that differences in enteral feeding regimens contribute to variation in the incidence of NEC between units (fig 1). ${ }^{4}$ Here, we summarise the current evidence for the effect of various enteral feeding practices on the risk of NEC and discuss the options for further research to clarify the uncertainties in this core aspect of care of the VLBW infant.

\section{BREAST MILK VERSUS FORMULA MILK FEEDING}

Observational studies have reported higher incidences of NEC in infants who receive only formula milk than in infants fully or partially fed with maternal breast milk. ${ }^{5}$ No randomised controlled trials of feeding VLBW infants with formula milk versus maternal breast milk have been carried out but meta-analyses of randomised trials of feeding with formula versus donor breast milk demonstrate a significantly higher risk of NEC in formulafed infants (fig 2). ${ }^{7-9}$ Surveillance and ascertainment biases may have contributed to the higher rate of detection of NEC in formula-fed infants as none of the trials blinded caregivers and assessors to the intervention. Furthermore, it is unclear whether any benefit of donor breast milk exists when given as a supplement to maternal breast milk rather than as a sole diet.

These findings endorse the practice of supporting mothers to express breast milk for their VLBW infant using evidence-based interventions. ${ }^{9}{ }^{10}$ Whether donor breast milk is the optimal alternative when maternal milk is not available also requires consideration of feasibility, costs, acceptability and the effect on other important clinical outcomes, principally nutrient intake, growth and development.

\section{Nutrient fortification of breast milk}

Expressed breast milk for feeding VLBW infants is commonly fortified with added nutrients. Although increasing the osmolality of the breast milk with fortifiers can delay gastric emptying and intestinal peristalsis, trials of nutrient fortification of breast milk have not found any evidence of an increased incidence of feed intolerance or NEC. ${ }^{11}{ }^{12}$

\section{TIMING OF INTRODUCTION AND RATE OF ADVANCEMENT OF ENTERAL FEEDS}

Multicentre benchmarking studies have found that the incidence of NEC is higher in neonatal centres where enteral feeding is introduced earlier, and feeding volumes are advanced more quickly. ${ }^{1}$ Data from observational studies have also suggested that the timing of the introduction and rate of advancement of enteral feeding may be modifiable risk factors for the development of NEC in VLBW infants. ${ }^{13}{ }^{14}$ However, the randomised trials undertaken to date have been insufficiently powered to determine which specific feeding strategies affect the risk of NEC (table 1). ${ }^{15-17}$

\section{Trophic feeding}

Trophic feeding (volumes up to about $24 \mathrm{ml} / \mathrm{kg}$ / day) compared with enteral fasting reduces the time taken to establish full feeding and the length of hospital stay without increasing the risk of NEC (table 1). ${ }^{18}$ Furthermore, evidence exists that mothers who express breast milk for early trophic feeding are more likely to continue to provide breast milk as the continuing principal form of nutrition for their infants. ${ }^{19}$

Only one trial has compared trophic feeding with progressive advancement of enteral feeds. ${ }^{20}$ Although the risk of NEC was lower in infants who received prolonged trophic feeds, this finding should be interpreted and applied cautiously. The trial was stopped early after an interim analysis and therefore the finding of an effect on the incidence of NEC may be spurious. In common with most feeding trials undertaken to date, 


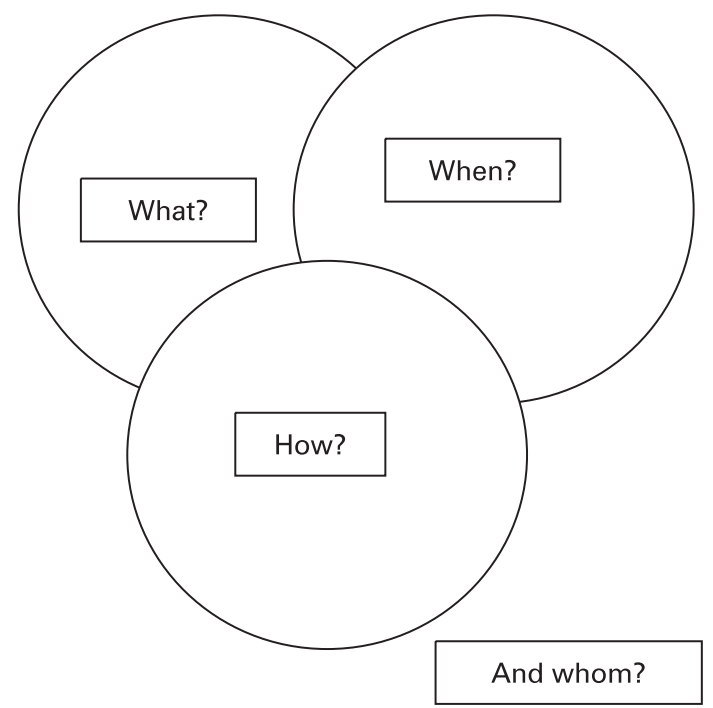

Figure 1 Feeding the VLBW infant.

caregivers and assessors were aware of the intervention. This may have resulted in several sources of bias that are likely to cause an overestimation of the incidence of NEC in infants whose feed volumes are being advanced (table 2). Furthermore, less than one-third of the study participants received breast milk, and enteral feeds were not introduced until on average 10 days after birth, a practice that is no longer typical in most neonatal centres.

Given the paucity of high-level evidence, the currently recommended strategies for early enteral feeding of VLBW infants tend to be conservative. It is generally considered safe to begin trophic feeding within about 5 days after birth, with human milk if possible, thereafter increasing the volume of feeds as tolerated in steps of about 10-20 ml/kg/day. However, this conservative approach may have important disadvantages for VLBW infants. Although NEC is a devastating condition in the $5 \%$ of VLBW infants affected, preventative strategies, including conservative feeding regimens, need to be applied to all at risk infants. The adverse consequences of delayed or slow advancement of enteral feeding may include prolonged use of parenteral nutrition with its attendant infectious and metabolic risks, delayed establishment of oral feeding, and prolonged duration of intensive care and hospital stay (fig 3). ${ }^{21}$ It has been argued that this "fear of NEC" should not be considered in isolation of other potential clinical outcomes in determining feeding policies and practice. ${ }^{22}$

\section{WHAT IS FEED INTOLERANCE (AND DOES IT PREDICT NEC)?}

Feeding regimens for VLBW infants are often interrupted by the development of signs of "feed intolerance", principally the detection of "gastric residuals," the gastric content aspirated before a planned gastric tube feed, and abdominal distension. Few studies have examined the clinical importance of these findings. The available data suggest that gastric residual volumes of up to $2 \mathrm{ml}$ in infants weighing less than $750 \mathrm{~g}$, or up to $3 \mathrm{ml}$ in heavier VLBW infants, are well tolerated and not associated with failure to establish full enteral feeding. Little evidence exists that the volume or colour (green, milky, clear) of gastric residuals is predictive of the risk of NEC for infants whose feed volumes are advanced conservatively. Similarly, the clinical importance of abdominal distension or bowel loops visible through the abdominal wall (without other features of

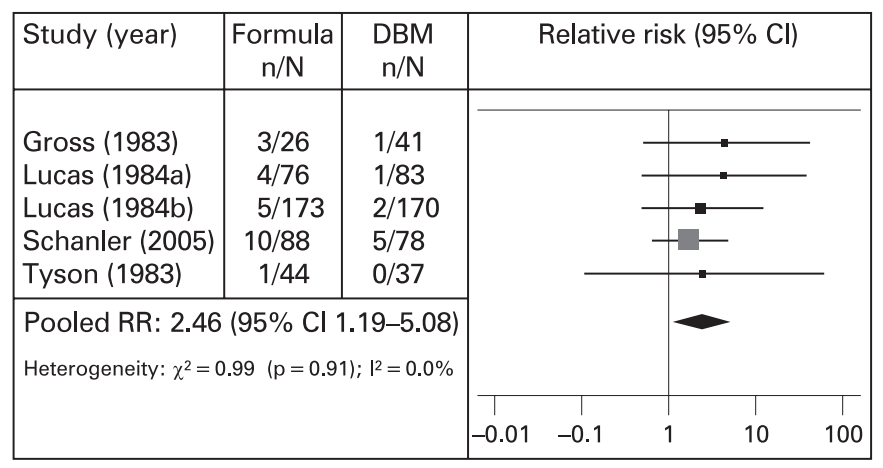

Figure 2 Meta-analysis of trials comparing feeding with formula versus donor breast milk-effect on risk of necrotising enterocolitis (adapted from Quigley et $\left.a^{8}\right)$. DBM, donor breast milk.

intra-abdominal disease) is unclear, especially in the modern era when early and prolonged use of continuous positive airway pressure results in intestinal gaseous distension. ${ }^{23} 24$

\section{INTRAUTERINE GROWTH RESTRICTION}

Infants who are growth-restricted in utero are considered to have a higher risk of developing NEC, especially if there has been antenatal detection of absent or reversed end-diastolic flow velocities (AREDFV) in Doppler studies of the fetal aorta or umbilical artery. However, the observational studies that have examined the association of AREDFV with NEC have reported inconsistent findings. ${ }^{25}$ This may be related to differences in study design, especially with regard to accounting for potential confounding variables, principally gestational age and birth weight. Studies that matched infants for gestational age and birth weight have not found any significant associations of AREDFV with NEC. Further developments of Doppler velocimetry may allow more precise definition of compromised fetuses at risk of adverse neonatal outcomes, including NEC, by mapping flow in the mesenteric, hepatic and middle cerebral arteries. Early postnatal evaluation of superior mesenteric arterial blood flow may also be developed as a tool to identify infants at increased risk of developing NEC. ${ }^{26}$

Paradoxically, most trials of enteral feeding regimens have specifically excluded infants with evidence of intrauterine growth restriction from participating because of the perceived high risk of developing NEC. The impact of early versus delayed enteral feeding in infants with AREDFV is currently being investigated in a large multicentre randomised controlled trial (http://www.npeu.ox.ac.uk/adept/, accessed 7 December 2007).

\section{GASTROINTESTINAL IMIMUNITY}

\section{Enteral immunoglobulin}

One of the potential mechanisms by which feeding with human breast milk reduces the risk of NEC is the delivery of immunoprotective factors such as secretory immunoglobulin A, lysozyme, epidermal growth factors and lactoferrin to the immature upper small intestine. For infants for whom human breast milk is not available, it is feasible that enteral supplementation with immunoglobulin (Ig) may have a protective effect. Although the Cochrane review of the trials of enteral immunoglobulin supplementation did not find any evidence of effect, most trials included used IgG rather than IgA. ${ }^{27}$ Further trials of enteral IgA prophylaxis are needed. 
Table 1 Cochrane reviews of enteral feeding strategies and the risk of necrotising enterocolitis

\begin{tabular}{llll}
\hline Intervention & $\begin{array}{l}\text { Number } \\
\text { of trials }\end{array}$ & $\begin{array}{l}\text { Total number } \\
\text { of participants }\end{array}$ & $\begin{array}{l}\text { Typical relative risk } \\
\text { (95\% } \mathbf{~ I ) ~}\end{array}$ \\
\hline $\begin{array}{l}\text { Delayed introduction } \\
\text { ( }>4 \text { days) vs earlier feeding }\end{array}$ & 1 & 60 & $0.53(0.11$ to 2.70$)$ \\
$\begin{array}{l}\text { Slow advancement }(<24 \mathrm{ml} / \\
\mathrm{kg} / \text { day }) \text { vs faster rates }\end{array}$ & 3 & 372 & $0.97(0.50$ to 1.87$)$ \\
$\begin{array}{l}\text { Trophic feeding }(<24 \mathrm{~m} / \mathrm{kg} / \\
\text { day) vs enteral fasting }\end{array}$ & 9 & 650 & $1.16(0.75$ to 1.79$)$ \\
$\begin{array}{l}\text { Continuous feeding vs bolus } \\
\text { feeding }\end{array}$ & 4 & 397 & $0.96(0.49$ to 1.90$)$ \\
\hline
\end{tabular}

\section{Gastric acidity}

Innate gastrointestinal immunity provided by gastric acid may be important in preventing the cascade of infectious and inflammatory events leading to NEC. A small randomised controlled trial found that acidification of milk with hydrochloric acid (median $\mathrm{pH} 3$ ) reduced the incidence of NEC in VLBW infants. ${ }^{28}$ Conversely, evidence exists that that the use of $\mathrm{H}_{2}$-blockers to suppress gastric acidity is associated with a higher risk of NEC (and nosocomial infection) in VLBW infants. ${ }^{29}$ Given the lack of evidence that gastro-oesophageal reflux is a cause of apnoea in preterm infants, it is recommended that use of $\mathrm{H}_{2}$-blockers should be restricted until robust evidence that benefits outweigh harmful effects is obtained. ${ }^{30}$

\section{Enteral antibiotics}

Evidence from controlled trials indicates that prophylactic enteral antibiotics (aminoglycosides or vancomycin) reduce the incidence of NEC in VLBW infants. ${ }^{31}$ There has been reluctance to adopt this practice because of concerns that such widespread antibiotic use would drive the emergence of antibiotic-resistant bacteria.

\section{Probiotics and prebiotics}

Recent trials have found that supplementing the diet of preterm infants with non-pathogenic "probiotic" bacteria, principally lactobacilli and bifidobacteria, reduces the incidence of NEC, nosocomial infection and all-cause mortality. ${ }^{32}{ }^{33}$ Questions of safety, including the risk of invasive infection with probiotic bacteria, remain and the optimal strains and dose regimens are not yet defined. Given the very encouraging results of trials to date, further studies that examine these issues are a research priority.

Adding "prebiotic" oligosaccharides to formula milk can also encourage the establishment of a balanced enteral microbial flora. These substances, naturally present in breast milk, are not

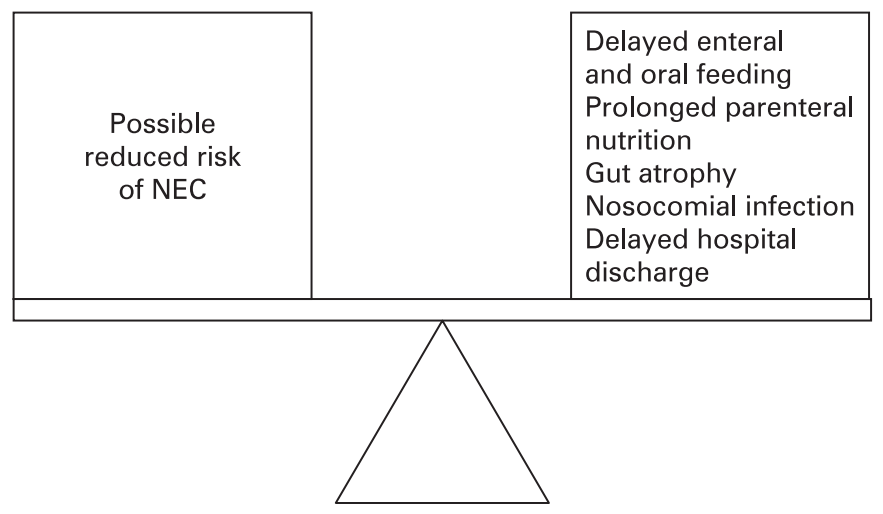

Figure 3 Slow/delayed enteral feeding: balance of risks.

degraded by gastric acid and support the growth of probiotic species in the bowel. Supplementing formula milk with a mixture of galacto- and fructo-oligosaccharides stimulates the growth in the intestine of bifidobacteria similar to those found in preterm infants fed human milk. ${ }^{34}$ To date, there have been no randomised controlled trials of the effect of prebiotics on feed tolerance and the risk of NEC in VLBW infants.

\section{Immunonutrition: arginine and glutamine}

Plasma levels of the amino acids arginine and glutamine are significantly lower during the early neonatal period in preterm infants who develop NEC than in similar-gestation infants who do not develop NEC. ${ }^{35}$ Arginine is involved in the generation of nitric oxide, a key mediator of intestinal vasomotor tone. It has been suggested that enteral arginine supplementation may enhance endothelial nitric oxide generation and thereby improve intestinal perfusion. The only trial to have examined this intervention found a reduced incidence of NEC in infants who received arginine. ${ }^{36}$ A large multicentre trial is needed to confirm this finding. ${ }^{37}$

Glutamine is the preferred respiratory fuel for rapidly proliferating cells including enterocytes and lymphocytes. It is abundant in human milk but present only in much lower levels in formula milk. Glutamine supplementation might therefore enhance mucosal integrity and intestinal barrier function in VLBW infants. However, evidence from good quality randomised trials suggests that the routine use of glutamine supplementation does not affect important clinical outcomes, including the risk of developing NEC. ${ }^{38}$ Instead, current research efforts are focused on the potential effect of glutamine supplementation on accelerating recovery in infants with established severe gastrointestinal disease. ${ }^{39}$

Table 2 Potential sources of bias in unblinded feeding trials (adapted from Tyson and Kennedy ${ }^{18}$ )

\begin{tabular}{ll}
\hline Type of bias & Details of bias \\
\hline Caregiver bias & $\begin{array}{l}\text { Knowledge of the feeding regimen may affect caregivers' responses to subjective signs of feed } \\
\text { intolerance }\end{array}$
\end{tabular}

Surveillance bias $\quad$ At the same true risk of developing NEC, more investigations (including abdominal radiographs) may be undertaken in one feeding group than in the other

Evaluator bias Clinical and radiographic diagnosis of NEC may be affected by the evaluator's knowledge of the feeding regimen 


\section{OTHER INDICATIONS FOR ENTERAL FASTING}

Because the pathogenesis of NEC may involve compromised gastrointestinal perfusion exacerbated by enteral feeding, it is speculated that enteral fasting may help reduce the risk of NEC when additional factors that compromise gut perfusion are present.

\section{Umbilical arterial catheter}

Evidence exists that enteral feeding while an umbilical arterial catheter (UAC) is in place does not affect superior mesenteric blood flow, the risk of feed intolerance or the incidence of NEC. ${ }^{40}{ }^{41}$ Data from randomised trials are insufficient to exclude an important effect on the UAC tip position ""high" (descending aorta above the level of the diaphragm) vs "low" (above the aortic bifurcation and below the renal arteries)) on the risk of NEC. However, high UAC tip placement results in a lower incidence of aortic thrombosis, fewer ischaemic complications and a longer duration of catheter use. ${ }^{42}$

\section{Patent ductus arteriosus and non-steroidal anti-inflammatory agents}

The presence of a patent ductus arteriosus (PDA) has been inconsistently reported as an independent risk factor for development of NEC. Currently, no evidence exists that a practice of withholding enteral feeds in infants with a PDA affects clinical outcomes. ${ }^{14}$ Similarly, meta-analyses of trials of non-steroidal anti-inflammatory agents for PDA closure have not demonstrated any significant effects on the incidence of NEC. ${ }^{43} 44$

\section{Red blood cell transfusion}

Although several case reports have described infants developing NEC during red blood cell transfusion, a large randomised controlled trial of high versus low thresholds for red blood cell transfusion in extremely low birth weight infants did not find an effect on the incidence of NEC. ${ }^{45}$ The currently available evidence is insufficient to conclude that adopting a policy of enteral fasting during blood transfusion cause more benefit than harm. ${ }^{46}$

\section{CONCLUSION}

The major modifiable risk factors for the development of NEC in VLBW infants relate to enteral feeding practices. Feeding preterm infants with human breast milk rather than formula milk can reduce the risk of NEC by about threefold. However, substantial clinical uncertainty remains about the effect of strategies such as delaying the introduction of enteral feeds, or slowly advancing feed volumes on the risk of NEC. Other interventions that merit further evaluation include the use of prebiotics and probiotics, the avoidance of $\mathrm{H}_{2}$-receptor blockers, and the use of arginine supplementation. Large multicentre trials within collaborative networks will be needed to examine these questions. Such trials should not focus on NEC as the sole outcome of interest given the subjectivity of this diagnosis and the existence of other distinct acute gastrointestinal conditions in VLBW infants such as spontaneous intestinal perforation and primary ischaemic necrosis of the bowel. Furthermore, since conservative feeding strategies may result in other "competing outcomes", principally nosocomial infection secondary to prolonged use of parenteral nutrition, it is essential that trials are powered and structured to assess the effect on long-term survival and neurodisability rates.

Competing interests: None.

\section{REFERENCES}

1. Fanaroff AA, Stoll BJ, Wright LL, et al. Trends in neonatal morbidity and mortality for very low birthweight infants. Am J Obstet Gynecol 2007;196:147.e1-8.

2. Rees CM, Pierro A, Eaton S. Neurodevelopmental outcomes of neonates with medically and surgically treated necrotizing enterocolitis. Arch Dis Child Fetal Neonatal Ed 2007:92:F193-8.

3. Brown EG, Sweet AY. Preventing necrotizing enterocolitis in neonates. JAMA 1978;240:2452-4.

4. Lucas A, Cole TJ. Breast milk and neonatal necrotising enterocolitis. Lancet 1990;336:1519-23.

5. Beeby PJ, Jeffery $H$. Risk factors for necrotising enterocolitis: the influence of gestational age. Arch Dis Child 1992;67:432-5

6. Henderson G, Anthony M, McGuire W. Formula milk versus maternal breast milk for feeding preterm or low birth weight infants. Cochrane Database Syst Rev 2007; (4):CD002972.

7. Boyd CA, Quigley MA, Brocklehurst P. Donor breast milk versus infant formula for preterm infants: systematic review and meta-analysis. Arch Dis Child Fetal Neonatal Ed 2007;92:F169-75.

8. Quigley MA, Henderson G, Anthony M, et al. Formula milk versus donor breast milk for feeding preterm or low birth weight infants. Cochrane Database Syst Rev 2007; (4):CD002971.

9. Fewtrell MS, Loh KL, Blake A, et al. Randomised, double blind trial of oxytocin nasal spray in mothers expressing breast milk for preterm infants. Arch Dis Child Fetal Neonatal Ed 2006;91:F169-74.

10. Jones $\mathbf{E}$, Spencer SA. Optimising the provision of human milk for preterm infants. Arch Dis Child Fetal Neonatal Ed 2007;92:F236-8.

11. Kuschel CA, Harding JE. Multicomponent fortified human milk for promoting growth in preterm infants. Cochrane Database Syst Rev 2004;(1):CD000343.

12. Fenton TR. Not all osmolality is created equal. Arch Dis Child Fetal Neonatal Ed 2006;91:F234.

13. Henderson G, Craig $S$, Brocklehurst $P$, et al. Enteral feeding regimens and necrotising enterocolitis in preterm infants: multicentre case-control study. Arch Dis Child Fetal Neonatal Ed Published Online First: 3 September 2007. doi:10.1136/ adc.2007.119560.

14. Patole SK, de Klerk N. Impact of standardised feeding regimens on incidence of neonatal necrotising enterocolitis: a systematic review and meta-analysis of observational studies. Arch Dis Child Fetal Neonatal Ed 2005;90:F147-51.

15. Kennedy KA, Tyson JE, Chamnanvanakij S. Early versus delayed initiation of progressive enteral feedings for parenterally fed low birth weight or preterm infants. Cochrane Database Syst Rev 2003;(4):CD001970.

16. Kennedy KA, Tyson JE, Chamnanvanakij S. Rapid versus slow rate of advancement of feedings for promoting growth and preventing necrotizing enterocolitis in parenterally fed low-birth-weight infants. Cochrane Database Syst Rev 2003; (4):CD001241.

17. Premji S, Chessell L. Continuous nasogastric milk feeding versus intermittent bolus milk feeding for premature infants less than 1500 grams. Cochrane Database Syst Rev 2003;(1):CD001819.

18. Tyson JE, Kennedy KA. Trophic feedings for parenterally fed infants. Cochrane Database Syst Rev 2005;(3):CD000504.

19. Schanler RJ, Shulman RJ, Lau C, et al. Feeding strategies for premature infants: randomised trial of gastrointestinal priming and tube-feeding method. Pediatrics 1999;103:434-9.

20. Berseth CL, Bisquera JA, Paje VU. Prolonging small feeding volumes early in life decreases the incidence of necrotizing enterocolitis in very low birth weight infants. Pediatrics 2003;111:529-34.

21. Flidel-Rimon 0, Branski D, Shinwell ES. The fear of necrotizing enterocolitis versus achieving optimal growth in preterm infants-an opinion. Acta Paediatr 2006;95:1341-4.

22. Flidel-Rimon 0, Friedman S, Lev E, et al. Early enteral feeding and nosocomial sepsis in very low birth weight infants. Arch Dis Child Fetal Neonatal Ed 2004;89:F289-92.

23. Mihatsch WA, von Schoenaich P, Fahnenstich $\mathrm{H}$, et al. The significance of gastric residuals in the early enteral feeding advancement of extremely low birth weight infants. Pediatrics 2002;109:457-9.

24. Cobb BA, Carlo WA, Ambalavanan N. Gastric residuals and their relationship to necrotizing enterocolitis in very low birth weight infants. Pediatrics 2004;113:50-3.

25. Dorling J, Kempley S, Leaf A. Feeding growth restricted preterm infants with abnormal antenatal Doppler results. Arch Dis Child Fetal Neonatal Ed 2005;90:F359-63.

26. Murdoch EM, Sinha AK, Shanmugalingam ST, et al. Doppler flow velocimetry in the superior mesenteric artery on the first day of life in preterm infants and the risk of neonatal necrotizing enterocolitis. Pediatrics 2006;118:1999-2003.

27. Foster J, Cole M. Oral immunoglobulin for preventing necrotizing enterocolitis in preterm and low birth-weight neonates. Cochrane Database Syst Rev 2004; (1):CD001816.

28. Carrion V, Egan EA. Prevention of neonatal necrotizing enterocolitis. J Pediat Gastroenterol Nutr 1990;11:317-23.

29. Guillet R, Stoll BJ, Cotten CM, et al. Association of $\mathrm{H}_{2}$-blocker therapy and higher incidence of necrotizing enterocolitis in very low birth weight infants. Pediatrics 2006;117:e137-42.

30. Di Fiore JM, Arko M, Whitehouse A, et al. Apnea is not prolonged by acid gastroesophageal reflux (GER) in preterm infants. Pediatrics 2005;116:1059-63.

31. Bury RG, Tudehope D. Enteral antibiotics for preventing necrotizing enterocolitis in low birthweight or preterm infants. Cochrane Database Syst Rev 2001;(1):CD000405. 
32. Schanler RJ. Probiotics and necrotising enterocolitis in premature infants. Arch Dis Child Fetal Neonatal Ed 2006;91:F395-7.

33. Deshpande G, Rao S, Patole S. Probiotics for prevention of necrotising enterocolitis in preterm neonates with very low birthweight: a systematic review of randomised controlled trials. Lancet 2007;369:1614-20.

34. Boehm G, Lidestri M, Casetta P, et al. Supplementation of a bovine milk formula with an oligosaccharide mixture increases counts of faecal bifidobacteria in preterm infants. Arch Dis Child Fetal Neonatal Ed 2002;86:F178-81.

35. Becker RM, Wu G, Galanko JA, et al. Reduced serum amino acid concentrations in infants with necrotizing enterocolitis. J Pediatr 2000;137:785-93.

36. Amin HJ, Zamora SA, McMillan DD, et al. Arginine supplementation prevents necrotizing enterocolitis in the premature infant. J Pediatr 2002;140:425-31.

37. Shah $\mathbf{P}$, Shah V. Arginine supplementation for prevention of necrotising enterocolitis in preterm infants. Cochrane Database Syst Rev 2007;(3):CD004339.

38. Tubman TRJ, Thompson SW, McGuire W. Glutamine supplementation to prevent morbidity and mortality in preterm infants. Cochrane Database Syst Rev 2005:(1):CD001457.

39. Grover Z, Tubman R, McGuire W. Glutamine supplementation for young infants with severe gastrointestinal disease. Cochrane Database Syst Rev 2007:(1):CD005947.
40. Havranek T, Johanboeke P, Madramootoo C, et al. Umbilical artery catheters do not affect intestinal blood flow responses to minimal enteral feedings. J Perinatol 2007;27:375-9

41. Davey AM, Wagner CL, Cox C, et al. Feeding premature infants while low umbilical artery catheters are in place: a prospective, randomized trial. J Pediatr 1994;124:795-9.

42. Barrington K. Umbilical artery catheters in the newborn: effects of position of the catheter tip. Cochrane Database Syst Rev 1999;(1):CD000505.

43. Fowlie PW, Davis PG. Prophylactic intravenous indomethacin for preventing mortality and morbidity in preterm infants. Cochrane Database Syst Rev 2003;(2):CD000174.

44. Shah SS, Ohlsson A. Ibuprofen for the prevention of patent ductus arteriosus in preterm and/or low birth weight infants. Cochrane Database Syst Rev 2006;(1):CD004213.

45. Kirpalani H, Whyte RK, Andersen C, et al. The Premature Infants in Need of Transfusion (PINT) study: a randomized, controlled trial of a restrictive (low) versus liberal (high) transfusion threshold for extremely low birth weight infants. J Pediatr 2006;149:301-7.

46. Agwu JC, Narchi H. In a preterm infant, does blood transfusion increase the risk of necrotizing enterocolitis? Arch Dis Child Fetal Neonatal Ed 2005;90:102-3.

\section{Images in neonatal medicine}

\section{Congenital hyperinsulinism: $\left[{ }^{18} \mathrm{~F}\right] \mathrm{DOPA}$ PET/CT scan of a focal lesion in the head of the pancreas}

Congenital hyperinsulinism (CHI) is a cause of severe hypoglycaemia in the neonatal period. ${ }^{1}$ The histological differentiation of CHI into focal and diffuse disease has radically changed the surgical management of patients with the disease. $^{2}$ Correct localisation and limited excision of the focal lesion results in complete cure of the patient. Recent advances in fluorine-18 L-3,4-dihydroxyphenylalanine ( $\left.\left[{ }^{18} \mathrm{~F}\right] \mathrm{DOPA}\right)$ positron emission tomography (PET) scanning are beginning to provide greater accuracy in preoperative differentiation of focal and diffuse disease and correct localisation of focal lesions. ${ }^{3-5}$ The principle of this test is that, pancreatic islets take up L-3, 4dihydroxyphenylalanine (L-DOPA), and convert it to dopamine by DOPA decarboxylase, present in the islet cells. However, the role of dopamine in pancreatic $\beta$-cells remains unclear.

A 3-day-old neonate presented with severe hyperinsulinaemic hypoglycaemia. He failed to respond to all forms of treatment and required further investigations to differentiate diffuse from focal disease. He underwent an integrated $\left[{ }^{18} \mathrm{~F}\right] \mathrm{DOPA}$ PET/CT scan. Figure 1 shows more than twofold uptake of $\left[{ }^{18} \mathrm{~F}\right] \mathrm{DOPA}$ in the head of the pancreas compared with the body and tail of the pancreas, proving focal disease. ${ }^{4}$ A computed tomography (CT) scan combined with the PET scan colocalised the focal lesion in the head of the pancreas at the junction of the portal vein and superior vena cava (size $6.1 \mathrm{~mm}$ ). At the time of surgery the focal lesion was found exactly where the PET/ CT localisation suggested and was excised with complete resolution of the hyperinsulinism. $\left[{ }^{18} \mathrm{~F}\right] \mathrm{DOPA}$ PET/CT scanning is now the preferred method for differentiating diffuse and focal CHI.

\section{R R Kapoor, ${ }^{1}$ C Gilbert, ${ }^{1}$ K Mohnike, ${ }^{2}$ 0 Blankenstein, ${ }^{3}$ F Fuechtner, ${ }^{3} \mathrm{~K}$ Hussain ${ }^{1}$}

${ }^{1}$ London Centre for Paediatric Endocrinology and Metabolism, Great Ormond Street, Hospital for Children NHS Trust, London, and The Institute of Child Health, London, UK; ${ }^{2}$ Department of Paediatrics and Neonatology, 0.-v.-Guericke-University Magdeburg, Germany; ${ }^{3}$ Institute of Experimental Paediatric Endocrinology, Charité-Universitätsmedizin Berlin, Germany

Correspondence to: Dr K Hussain, Developmental Endocrinology Research Group, Molecular Genetics Unit, Institute of Child Health, University College London, 30 Guilford Street, London WC1N 1EH, UK; K.Hussain@ich. ucl.ac.uk

\section{Competing interests: None.}

Arch Dis Child Fetal Neonatal Ed 2008;93:F166. doi:10.1136/adc.2007.121178

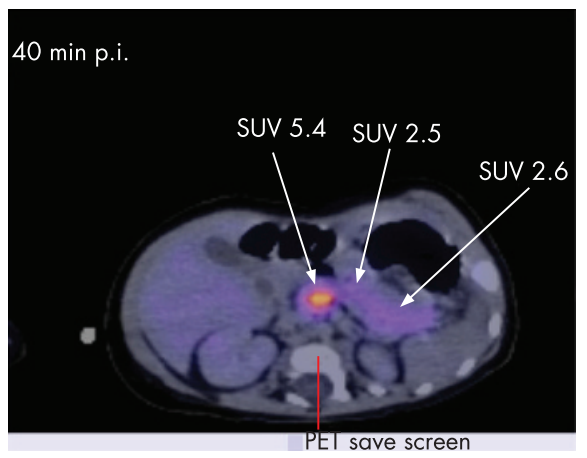

Figure 1 For comparison of tracer uptake in various parts of the pancreas standardised uptake values (SUVs) were calculated: $\left[{ }^{18} \mathrm{~F}\right] \mathrm{DOPA}$ uptake is greatest in the head $(5.4)$ of the pancreas compared with the body and tail (2.5 and 2.6, respectively), demonstrating the location. The size of the focal lesion was estimated to be $6.1 \mathrm{~mm}$ in diameter.

\section{REFERENCES}

1. Hussain K. Congenital hyperinsulinism. Semin Fetal Neonatal Med 2005;10:369-76.

2. Rahier J, Guiot $Y$, Sempoux C. Persistent hyperinsulinaemic hypoglycaemia of infancy: a heterogeneous syndrome unrelated to nesidioblastosis. Arch Dis Child Fetal Neonatal Ed 2002;82 F108-12.

3. Otonkoski T, Nanto-Salonen K, Seppanen M, et al. Diagnosis of focal hyperinsulinism of infancy with [18F]DOPA positron emission tomography. Diabetes 2006;55:13-8.

4. Mohnike K, Blankenstein O, Christesen HT, et al. Proposal for a standardized protocol for F-DOPA-PET (PET/CT) in congenital hyperinsulinism. Horm Res 2006;66:40-2.

5. Hardy $\mathbf{0 T}$, Hernandez-Pampaloni M, Saffer JR, et al. Diagnosis and localization of focal congenital hyperinsulinism by (18)F-fluorodopa PET scan. J Pediatr 2007;150:140-5. 